Fanum

Sociológico

\section{Forum Sociológico}

Série II

$29 \mid 2016$

Número 29

\title{
Empowerment of woman through agroecological fairs in the city of Ilhéus, Bahia/Brazil
}

Emponderamento da mulher através de feiras agroecológicas na cidade de Ilhéus, Bahia/Brasil

Marcella Gomez, Emerson Antônio Rocha Melo de Lucena, Ana Cristina de Souza Mandarino e Estélio Gomberg

\section{CpenEdition}

\section{Journals}

Edição electrónica

URL: https://journals.openedition.org/sociologico/1505

DOI: 10.4000/sociologico.1505

ISSN: $2182-7427$

Editora

CICS.NOVA - Centro Interdisciplinar de Ciências Sociais da Universidade Nova de Lisboa

Refêrencia eletrónica

Marcella Gomez, Emerson Antônio Rocha Melo de Lucena, Ana Cristina de Souza Mandarino e Estélio Gomberg, «Empowerment of woman through agroecological fairs in the city of Ilhéus, Bahia/Brazil», Forum Sociológico [Online], 29 | 2016, posto online no dia 31 dezembro 2016, consultado o 30 março 2022. URL: http://journals.openedition.org/sociologico/1505 ; DOI: https://doi.org/10.4000/ sociologico. 1505 


\title{
EMPONDERAMENTO DA MULHER ATRAVÉS DE FEIRAS AGROECOLÓGICAS NA CIDADE DE ILHÉUS, BAHIA/BRASIL EMPOWERMENT OF WOMAN THROUGH AGROECOLOGICAL FAIRS IN THE CITY OF ILHÉUS, BAHIA/BRAZIL
}

\author{
Marcella Gomez \\ Universidade Estadual de Santa Cruz-Bahia, Departamento de Ciências Biológicas \\ Emerson Antônio Rocha Melo de Lucena \\ Universidade Estadual de Santa Cruz-Bahia, Departamento de Ciências Biológicas \\ Ana Cristina de Souza Mandarino \\ Universidade Federal da Bahia, Escola de Administração \& Programa de Estudos, Pesquisas e Formação em Políticas e \\ Gestão de Segurança Pública \\ Estélio Gomberg \\ Universidade Estadual de Santa Cruz-Bahia, Departamento de Filosofia e Ciências Humanas
}

\begin{abstract}
Resumo
O foco principal deste artigo é apreender a importância das mulheres na militância agroecológica, enfatizando as suas atuações e influência nas feiras agroecológicas realizadas na cidade de Ilhéus, Estado da Bahia, Brasil. Apesar desta significativa e crescente atuação, as mulheres agricultoras enfrentam uma série de dificuldades no que respeita ao reconhecimento de seu trabalho de produção de alimentos, dificuldade no acesso à terra e/ou a comercialização direta dos produtos somada às atividades laboriais no espaço doméstico. Registamos uma valorização, por parte dos consumidores, desta modalidade de comercialização de agricultura orgânica, gerando uma maior fidelização com maior confiança pelo fato de ter sido produzida e comercializado por mulheres, denotando valores de qualidade de vida e alimentos saudáveis. Fica clara a importância destas feiras como espaços para geração de emprego e rendimentos, troca de saberes, valorização da cultura do campo e da mulher, e ainda a desconstrução de ideologias, atitudes e mentalidades discriminatórias e preconceituosas que regem, em geral, a estrutura social na Bahia.
\end{abstract}

Palavras-chave: emponderamento feminino, feiras agroecológicas, Bahia

\begin{abstract}
The main focus of this article is to understand the importance of women in the agroecological militancy, emphasizing, their performances and influence in the agroecological fairs, performed in the city of Ilhéus, Bahia State, Brazil. Despite this significant and increasing actuation, the women agroecological face a number of difficulties in terms of the recognition of their work of food production, difficulty in gaining access to land and/or the direct marketing of products plus labor activities in the domestic space. We recorded an exploitation on the part of consumers to this modality of marketing of organic agriculture on the part of women and generating a greater customer loyalty, with increased reliability due to have been produced and marketed by women, denoting values of quality of life and healthy food. Is clear the importance of these fairs as spaces for the generation of employment and income, exchange of knowledge, culture appreciation of the field and of the woman, deconstruct ideologies, attitudes and mentalities discriminatory and prejudiced governing, in general, the social structure in Bahia.
\end{abstract}

Keywords: female empowerment, agroecological fairs, Bahia 


\section{Introdução}

A agricultura familiar, de modo geral, é a grande responsável pela produção de alimentos no Brasil e no mundo. No entanto, essa atividade ocupa um lugar secundário e subalterno na economia brasileira quando comparada ao campesinato em outros países (Melo, 2002: 3). A agricultura familiar é um conceito utilizado para caracterizar unidades de produção rural, estruturadas no trabalho familiar, o qual se identifica pela relação entre a terra, o trabalho e a família (Mesquita e Mendes, 2012: 1).

Referindo a padrões de racionalidade desta modalidade de agricultura, Assis (2006) aponta que "(..) fogem à lógica de mercado de máxima eficiência económica, e trilham o caminho do ótimo e satisfatório possível, onde a organização desejada não visa atender aos padrões estabelecidos pelas demandas de mercado, mas, sim, às necessidades de satisfação e desejo subjetivadas na lógica da produção familiar" (Assis, 2006: 79).

A agricultura familiar apresenta uma série de variações as quais se baseiam nas relações com o espaço e com o sistema de trabalho no vínculo entre família e entorno sociocultural. De acordo com a Organização das Nações Unidas para a Agricultura (FAO) e Instituto Nacional de Colonização e Reforma Agrária (INCRA) do Brasil, a agricultura familiar define-se por três características: i) a gerência da produção rural é feita pela família; ii) o trabalho é desenvolvido em sua maior parte pela família e iii) os fatores de produção pertencem à família.

Nesse modelo de produção agrícola, o trabalho feminino é o que de fato contribui para a sobrevivência do grupo familiar, isso porque são as mulheres agricultoras as responsáveis pelas atividades de manutenção do núcleo familiar, pelos quintais, onde realizam atividades agrícolas e criam os animais. Apesar de contribuir com a renda familiar, o trabalho feminino no campo ainda é considerado por muitos como atividade complementar, sem valor e invisível dentro do setor produtivo (Brumer, 2004; Almeida et al., 2014: 37-41).

A atividade da mulher na agricultura familiar quando considerado como "ajuda", revela que a atividade agrícola é da responsabilidade e obrigação masculina, transmite a ideia de que a mulher não faz parte da agricultura familiar e estimula o ideal de patriarcado, que por vezes se encontra presente na mente das próprias mulheres. Entretanto, essa ideia de que a mulher é apenas uma ajudante, tem-se transformado, através da conquista de direitos sobre o acesso a terra, a recursos financeiros e cargos de liderança dentro de movimentos sociais.

A ampliação significativa da importância feminina no campo desencadeou-se principalmente com a Constituição Brasileira de 1988, quando no artigo 226 , parágrafo $5^{\circ}$ foi reconhecida a igualdade entre homens e mulheres na família. Enquanto isso, no artigo 189, parágrafo único, foi estabelecida a igualdade de direitos entre homens e mulheres na obtenção de título de domínio ou concessão de terras para fins de reforma agrária. No entanto, além das Leis é necessário um conjunto de ações paralelas que empoderem as mulheres de seus direitos conquistados (Sales, 2007: 441).

Organizarem-se em comissões, coletivos, movimentos entre outros grupos, incentiva o fortalecimento pessoal e conjunto das mulheres trabaIhadoras rurais, assim como contribui com a ruptura da rígida divisão de papéis já pré-determinado pela família e também pelos modelos convencionais de organização social. A partir desse movimento de empoderamento, as trabalhadoras rurais começam a produzir, reagem aos processos de submissão e experimentam a liberdade económica e social.

"A organização das trabalhadoras estimula suas lideranças a pensar sobre as desigualdades de género, e, a partir desse olhar, as trabalhadoras começam a discutir sobre a invisibilidade do seu trabalho na agricultura familiar camponesa. As trabalhadoras rurais percebem que as atividades produtivas desenvolvidas no grupo familiar têm um significado económico; não são simplesmente uma ajuda" (Sales, 2007: 439).

Região historicamente exportadora de trabalho no Brasil, o Nordeste, tem passado por transformações sociais e culturais que vêm contribuindo para a fixação do homem no campo, assim como ocorre em outras regiões deste país, através de incentivos fiscais ao desenvolvimento de atividades de produção orgânica. No entanto, é nas feiras livres que o produto dos esforços dessa transformação é comercializado, mais nem sempre reconhecido.

Na região Sul do Estado da Bahia, na cidade de Ilhéus, organizou-se um canal de comercialização a partir do ano de 2014, para produtos diferenciados, orgânicos, uma feira agroecológica, a qual proporcionou uma melhora na qualidade de vida e aumento na renda dos produtores que participam dessa atividade semanal.

A participação feminina nesta feira é maioritária - onze mulheres entre dezesseis participantes no total - entre os produtores e colaboradores, que contribuem com a feira a partir da exposição de produtos artesanais ligados a economia criativa local, fato que tem estimulado a participação feminina durante a realização da feira e contribuído para a diversificação dos produtos comercializados.

A Economia Criativa é definida por um processo atual com a propósito de desenvolver estratégias de soluções face a adversidades apresentadas em diversas áreas e que visam o uso de novas técnicas, 
modificação de valores e de práticas, produção e distribuição de produtos e serviços, preconizando os elementos do capital intangível: o conhecimento, a criatividade, a experiência, a cultura e o capital intelectual (Howkins, 2007).

Este autor aponta a existência de duas modalidades de criatividade, na intersecção das realizações das ações humanas e geração de produto, ou seja: a primeira é uma instância social presente nas diversas sociedades, enquanto a segunda é mais expressiva em sociedades industriais devido à inserção de valor na inovação tecnológica e sobre a propriedade intelectual.

Conjugando o quadro conceitual apresentado por Howkins (2001) e a perspectiva adotada na Conferência das Nações Unidas sobre Comércio e Desenvolvimento (UNCTAD, 2010), pode-se afirmar que a economia criativa:

- É o conjunto de atividades económicas que dependem do conteúdo simbólico - nele incluído a criatividade já citada, como fator mais expressivo para a produção de bens e serviços;

- É um conceito em evolução com base em recursos criativos potencialmente geradores de crescimento e desenvolvimento económico;

- Pode promover ganhos de geração de renda, criação de emprego e exportação, promovendo a inclusão social, a diversidade cultural e o desenvolvimento humano;

- Abrange aspectos económicos, culturais e sociais que interagem com a tecnologia e propriedade intelectual numa mesma dimensão e tem relações de interação muito próximas com o turismo e o desporto.

É interessante apontar o crescimento da importância do conceito na última década, registado pelo papel da criatividade como uma força na vida económica contemporânea, especificamente no Brasil, pela riqueza cultural, utilizando recursos para o aumento da participação na economia global e, por efeito, proporcionando a inclusão social, a diversidade cultural e o emponderamento.

$\mathrm{Na}$ cidade de Ilhéus, a feira agroecológica não movimenta apenas produtores e artesãos, mas também a comunidade local, que visa uma melhor qualidade de vida, valorizações culturais locais a partir da ingestão de alimentos oriundos da agricultura familiar de base orgânica.

Este fenômeno social do desejar estar conectado com produtos oriundos de agroecologia traz em cena a valorização da natureza por produções materiais e imateriais do pertencer ao "natural" e consideramos como um fenômeno global manifesto na contemporaniedade e por efeito, a "natureza" e a "cultura" devem ser apreendidas como construções culturais para seu funcionamento como dispositivos para a construção cultural, da sociedade humana, do género e da economia (MacCormack e Strathern, 1980).

Após observações naturalísticas, também descritas como não participantes, das feiras agroecológicas que ocorrem na cidade de Ilhéus, foi possível analisar o número de participantes, tanto comerciantes quanto consumidores, as relações socias de compra e venda entre ambos e a aceitabilidade do público sobre os produtos comercializados. Fotografias e documentos, em que estão registadas as atividades ligadas à realização de feiras na cidade de Ilhéus foram igualmente analisados.

Através das observações naturalísticas, não participantes, e das análises documentais foi possível avaliar que a presença feminina na feira além de unânime, contribui para a aceitação e reconhecimento dos produtos agrícolas como realmente saudáveis, isso porque, a mulher apresenta uma maior preocupação com a origem do alimento que comercializa, com a qualidade do alimento e em estabelecer uma relação de confiança com os "fregueses" que as procuram nesse espaço de comércio. Optou-se por não fazer contato por meio de entrevistas ou questionários tendo em vista as implicaçoes éticas dessa ação.

\section{A mulher e o empoderamento feminino}

O campo de estudos de género consolidou-se no Brasil no final dos anos de 1970, ao mesmo tempo em que se consolidava o movimento feminista do país (Farah, 2004: 47). Embora historicamente as mulheres participem das lutas e movimentos sociais no campo, a história de movimentos específicos de mulheres trabalhadoras rurais no Brasil é relativamente recente, levando em consideração que as primeiras organizações exclusivas de mulheres rurais datam dos anos de 1980 (Heredia e Cintrão, 2006: 6).

Conforme Deere (2004: 177) o movimento autónomo de mulheres rurais, atualmente ligado à Articulação Nacional das Mulheres Trabalhadoras Rurais, tem suas raízes nas atividades dos comitês eclesiais de base nas décadas de 1960 e 1970 . Incentivadas pela igreja católica, movimentos sindicais e partidos políticos, a organização feminina para luta dos direitos de igualdade de género tomou maior força no sul do país, especialmente nos Estados da Região Sul, do Rio Grande do Sul e de Santa Catarina, e no Nordeste, principalmente na Paraíba e em Pernambuco. Esses processos regionais se consolidaram com a fundação do "Movimento de Mulheres Trabalhadoras Rurais do Nordeste" em 1986 e em 1989 a fundação do "Movimento de Mulheres Trabalhadoras Rurais do Rio Grande do Sul". 
O despertar para a luta coletiva pelo reconhecimento do trabalho no campo, culminou num conjunto de eventos dentre os quais estão à aprovação da Década da Mulher (1975-1985), a institucionalização do Dia Internacional da Mulher em 1975 e a realização de Conferências Mundiais que objetivavam debater a situação da mulher no campo (Sales, 2007: 438) e com isso incentivá-las a participarem das atividades políticas e económicas das suas comunidades, tendo por finalidade afirmar que as diferenças entre homens e mulheres não podem ser utilizadas como parâmetros para julgar como menores as competências políticas das mulheres (Sales, 2007: 439).

De acordo com Melo (2006: 5) ao nível mundial, as agricultoras contribuem ativamente para a produção de alimentos básicos, sendo responsáveis por mais de $50 \%$ dos géneros alimentícios produzidos. Para Rodrigues (2012: 7), se as condições entre homens e mulheres do campo fossem igualitárias, a produção agrícola dos países em desenvolvimento teria um acréscimo de 2,5 a 4\%, o que poderia reduzir o número de pessoas famintas no mundo em 12 a 17 \%. Dessa forma, fica evidente a importância das mulheres do campo como protagonistas no processo de mudança no sistema de produção agrícola e no enfrentamento de políticas machistas, assistencialistas e clientelistas.

Karam (2004: 314) em seu trabalho com mulheres produtoras orgânicas na Região Metropolitana da Cidade de Curitiba, no Estado do Paraná, analisa que, em situação de entrevista com os membros da família, estes destacaram que foram as mulheres que assumiram a decisão pelos primeiros riscos da conversão do sistema de produção. No estado do Paraná as produtoras orgânicas iniciaram a instalação e preparação de pequenas hortas no entorno das casas, buscando as primeiras orientações técnicas, fazendo os primeiros preparados a serem utilizados no processo de produção orgânica, experimentando novas sementes, colhendo os frutos para as primeiras produções e se responsabilizando pela comercialização.

Segundo Narciso e Henriques (2008: 4) as mulheres desempenham um papel fundamental em três níveis: i) a um nível macro são importantes como recurso para a força de trabalho (remunerado ou não), ii) ao nível de agregado familiar são produtoras de produtos e serviços para o mercado e para uso doméstico e iii) a um nível intergeracional como cuidadoras e educadoras dos mais novos, sendo responsáveis pela alimentação, saúde e socialização das novas gerações, atuando desse modo como um importante agente de transformações.

Famílias produtoras rurais de base agroecológica e orgânica têm nas mulheres as suas principais agentes de multiplicação e reprodução, isso porque na sua maioria, não buscam o imediatismo da agricultura convencional, tão mais requisitada pelo género masculino, mais sim a qualidade de vida proporcionada pelo consumo de alimentos saudáveis.

Desconsiderar o trabalho da mulher na agricultura familiar é deixá-la invisível, é ignorar a sua contribuição económica na produção agrícola. É preciso dar visibilidade ao trabalho da mulher, não somente na agricultura familiar, mas em todos os campos de trabalho, repensando o conceito de trabalho e das múltiplas variáveis relacionadas com esse tema (Melo, 2002: 13).

No entanto, as limitações ainda enfrentadas pelas trabalhadoras rurais em seu cotidiano, para desenvolver as suas atividades são, de acordo com Garcia (2004: 90), verificadas pela invisibilidade do seu trabalho produtivo como componente integrante da produção, pelo fato do trabalho reprodutivo (cozinhar, lavar, passar, limpar, cuidar dos filhos) não ser considerado trabalho e pelo fato de que as atribuições de valor para as atividades produtivas são diferenciadas de acordo com o sexo.

Para muitas mulheres, a militância agroecológica, através do trabalho no campo, foi o espaço necessário às ações de empoderamento político. Foi também a partir desses espaços que elas puderam manifestar as suas discordâncias e insatisfações com os sistemas atuais de produção e buscar alternativas para construir uma sociedade mais justa e igualitária (Siliprandi, 2009: 146).

O reconhecimento da agricultura familiar dentro de uma perspectiva integradora permite que a sociedade reconheça a importância do papel das atividades agroecológicas, o que evidencia o papel desempenhado pelas agricultoras de modo a destacar a importância da mulher dentro da lógica produtivista da agricultura (Herrera, 2013: 4).

A importância em reconhecer os direitos da mulher à terra, acontece geralmente a partir do argumento produtivista e de empoderamento. Enquanto o argumento produtivista defende que o direito das mulheres à terra está associado ao aumento do bem estar de mulheres, dos seus filho e comunidade tendo em vista o bem comum da produtividade, o argumento de empoderamento reconhece que os direitos das mulheres à terra são decisivos para aumentar o seu poder de barganha dentro da família e da comunidade, contribuindo dessa forma para uma real igualdade entre homens e mulheres (Deere, 2004: 176-177).

De acordo com Sales (2007: 438) o processo de organização das trabalhadoras rurais numa rede de comunicação e significados, resultou na criação da Articulação Nacional de Mulheres trabalhadoras rurais, em 1995, o que permitiu o crescimento dos movimentos de mulheres rurais a partir da possibilidade de se afirmarem como portadoras de um saber-poder no campo da política conferindo- Ihes a capacidade de repensarem o seu cotidiano e competências. 
A autora apresenta como exemplo a organização das mulheres rurais do Estado do Ceará, a qual permitiu o crescimento de grupo de mulheres e o aparecimento de lideranças e com isso a maior participação das mulheres no campo político.

Outro exemplo de organização política feminina ocorreu na Região Centro-Oeste, no Estado do Mato Grosso a partir de um grupo de mulheres assentadas no Projeto de Assentamento Margarida Alves, na Cidade de Mirassol d'Oeste. Essa organização se deu pela necessidade de melhor atendimento médico à comunidade e para discutir a valorização da mulher. Para Ferreira Mendes e colaboradores (2014: 79) a partir dessa organização, as mulheres do PA Margarida Alves transformaram a sua realidade económica, o que permitiu a mudança na hierarquia das famílias camponesas e também nos espaços dos assentamentos, pois com as conquistas de direitos políticos, sociais e económicos as mulheres não só passaram a contribuir financeiramente como também para o maior desenvolvimento e consolidação dos assentamentos.

A organização de movimento de mulheres que vem acontecendo na cidade de Ilhéus, conta não apenas com o argumento produtivista, mais também de empoderamento cultural, político e económico através da participação destas nas feiras agroecológicas desta cidade.

A participação de mulheres nessas feiras proporciona uma diversificação de produtos, relações mais cordiais e sinceras com consumidores e maior valorização do trabalho feminino na geração de emprego e renda da cadeia produtiva dos produtos agrícolas locais, assim como produção do artesanato ligado à cadeia produtiva dos núcleos de Economia Criativa da cidade.

Atualmente, as feiras agroecológicas não são canais exclusivos de comercialização dos produtos oriundos da agricultura familiar de base agroecológica e da produção orgânica. Essas mulheres ainda participam dos núcleos de Economia Solidária da cidade de Ilhéus, otimizando o uso desses espaços para comercialização, a distribuição e a popularização de produtos saudáveis e exclusivos da cadeia artesã ilheense, contribuindo para a dinâmica da economia local e valorização da cultura regional.

A participação do género feminino nas feiras agroecológicas provoca a fidelização dos consumidores, assim como a associação entre os conceitos: qualidade de vida e alimentos saudáveis. A correlação destes conceitos com a participação das mulheres nas atividades de comercialização, distribuição e produção de alimentos agroecológicos e artesanais ligados à Economia Criativa, fazem das feiras um sucesso sociocultural e económico.

\section{Feiras agroecológicas e transformações socioculturais}

Para Le Goff (1992), no período medieval, as feiras constituíam um lócus de convergência de produtores do espaço rural com o urbano, ao oferecer suas produções agrícolas, animais e outros, desencadeiam um processo de alto nível de sociabilidade nestas relações de compra e venda, transmissões de informações e marcações no espaço da cidade.

Ao analisar a forma precursora das feiras livres do início do século XX, na então capital federal do Brasil República, Parga (1996) assinala as reuniões de mulheres negras ao ar livre, em pontos preestabelecidos, para a comercialização de produtos da pequena lavoura, de animais e da indústria doméstica e, anos depois, com agregações de outros grupos de imigrantes, ao comércio de varejo nos espaços urbanos concebendo as feiras livres como espaço de movimentações populares com fins comerciais e sociais.

Assim, as feiras constituem uma instância de estrutura social vinculada às práticas que se desenvolvem ao longo do ano, e que só são possíveis a partir da disponibilidade de produtos que caracterizam as distintas comunidades que participam dessa atividade semanal (Lambaré; Vignale; Pochettino, 2015: 8). O conhecimento associado a está atividade promove uma alternativa alimentícia que se mantém vigente ao acionar o cotidiano que encoraja a conservação e perpetuação dos saberes tradicionais (Lambaré, 2014: 129).

Figura $1 \triangleright$ Feira Livre em Ilhéus em 1958

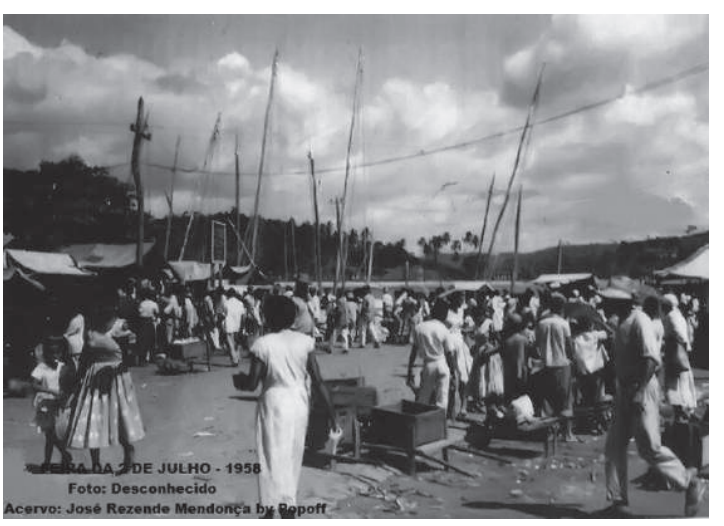

A primeira feira de produtos de base orgânica da cidade de Ilhéus foi uma iniciativa da parceria entre a Universidade Estadual de Santa Cruz (UESC) e o Instituto Cabruca, organização não governamental que atua junto a assentamentos de reforma agrária e comunidades tradicionais a partir da Assistência Técnica Rural. A organização de uma atividade prática, objetivando os desdobramenos teóricos do 
evento, culminou na realização da I feira de produtos agroecológicos da cidade de Ilhéus, realizada nas dependências da Universidade Estadual de Santa Cruz, onde ocorreu Simpósio de Agroecologia.

Realizar a feira durante um evento científico, no interior de uma Instituição de Ensino Superior Estadual, proporcionou às famílias agricultoras da região uma aproximação com a comunidade local, participantes do curso e comunidade académica, contribuindo dessa forma para a divulgação, comercialização e popularização dos produtos oriundos da produção familiar de base orgânica com a circularidade de conhecimentos entre diversos campos sociais.

Nesta interação, sujeitos possuidores de um quantum de capital de naturezas distintas, seja ele capital cultural, capital social, capital político, capital artístico, capital desportivo, capital económico etc., estão a criticar ou a aceitar certas diretrizes que redefinem as bases da sociedade.

Para Bourdieu (1989): "Sem dúvida, os agentes constróem a realidade social; sem dúvida, entram em lutas e relações visando a impor sua visão, mas eles fazem sempre com pontos de vista, interesses e referenciais determinados pela posição que ocupam no mesmo mundo que pretendem transformar ou conservar" (Bourdieu, 1989: 8).

Tendo em vista que a alimentação humana é um ato social e cultural onde o consumo de alimentos põe em jogo um conjunto de fatores de ordem ecológica, histórica, cultural, social e económica ligados a uma rede de representações, simbolismos e rituais, é necessária a construção de identidades coletivas capazes de expressarem relações sociais e de poder (Álvarez, 2005: 11).

Procurando construir essa identidade coletiva foi proposto o nome Feira Agroecológica o qual surgiu da necessidade de estabelecer um conceito para a venda de produtos agrícolas advindos da agricultura familiar, que estavam e/ou estão, em processo de transição, ou seja, que deixaram de ser cultivados a partir de técnicas ligadas aos pacotes tecnológicos da Revolução Verde, e passaram a utilizar tecnologias alternativas e sustentáveis de produção, que visam o cultivo, distribuição e comercialização de alimentos livres de defensivo agrícola.

O termo agroecológico foi usado junto com os conceitos de comércio socialmente justo, economicamente viável e ambientalmente correto, pois os participantes não possuíam, até então, o selo de produto orgânico, o qual é liberado após uma série de exigências propostas pelo Ministério da Agricultura, Pecuária e Abastecimento do Brasil. No entanto, os produtos comercializados atenderam as exigências do Simpósio: estimular a mudança de hábitos alimentares e valorizar a produção das famílias agricultoras da região sul baiana.
Durante o Simpósio foram comercializados doces, biscoitos, compotas, hortaliças, frutas e legumes, pelos próprios produtores, o que creditou maior valor cultural e económico aos produtos disponíveis durante o evento.

Essa comercialização provocou nos agricultores e agricultoras uma valorização pessoal quanto à sua importância na cadeia produtiva de alimentos saudáveis, além da troca de saberes com a comunidade académica, como assinalamos acima. Exemplo semeIhante ocorre na cidade de Juella, Argentina, onde a feira se organiza em postos de comida, venda de produtos de origem animal (carne de cordeiro, vaca e queijo) e vegetal (frutas, plantas medicinais, feijão entre outros produtos), contribuindo dessa maneira para o fortalecimento cultural dos produtos de cada região (Lambaré, Vignale e Pochettino, 2015: 11).

A realização da feira agroecológica não findou com o termino do evento, em espaço cedido pela Universidade Estadual de Santa Cruz no interior da mesma, a feira de produtos agroecológicos perpetuou-se e completou um ano em Outubro de 2015. Atualmente a feira acontece todas as sextas feiras no horário matutino e encontra-se registada nacionalmente no mapa de Feiras Orgânicas do Instituto Brasileiro de Defesa do Consumidor (IDEC), organização não governamental voltada aos direitos de consumidores.

A participação feminina durante a feira realizada inicialmente como ação do Simpósio de Agroecologia e nas que se seguiram, é sobremaneira relevante, não só porque a participação das mulheres na agricultura orgânica representa o papel fundamental que esta exerce em todo processo, como também porque, no campo de produção, as mulheres têm sido precursoras dentro da unidade familiar. Assumem o desafio de começar algo novo pondo em prática os saberes adquiridos com outras gerações, tais como a introdução de sementes guardadas nas hortas caseiras, a recuperação em todas as esferas de produção e a cooperação entre as unidades da família e comunidade (Karam, 2004: 304).

Segundo Karam (2004: 314) as mulheres protagonizam a conversão da produção agrícola convencional para a orgânica, isso porque se preocupam com o alimento que oferecem aos seus descendentes. A mulher assume o papel de mãe, esposa e filha diante/em face daqueles que compram os seus produtos, o que lhes confere maior consciência sobre a importância da transição agrícola dos modelos convencionais para os modelos agroecológicos e orgânicos, sendo elas as protagonistas nesse processo de mudança.

Tendo em vista o sucesso da feira agroecológica realizadas na UESC, foi proposto aos agricultores e agricultoras participantes que estendessem as suas atividades para o sábado, em local cedido pela prefeitura municipal de Ilhéus. 


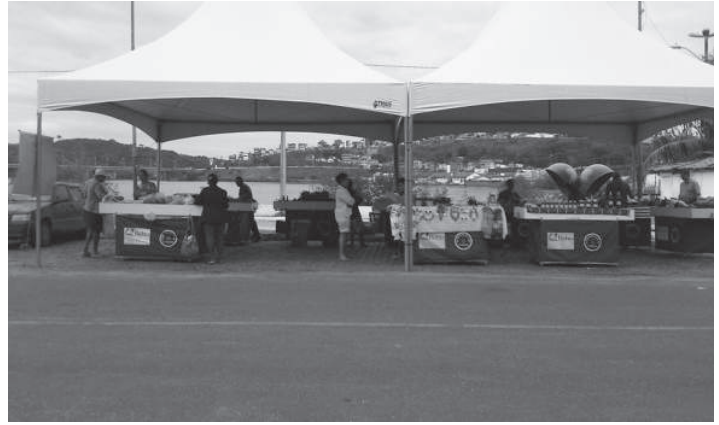

Figura $2 \triangleright$ Feira Agroecológica em Ilhéus, 2015. Acervo particular de Marcella Garcez

O local destinado foi o centro histórico da cidade, onde nas décadas de 1960-1970 era realizada uma feira de compra e venda de produtos agrícolas, de utensílios domésticos, roupas entre outros artefatos, no entanto, em um modelo diferente do atual. A feira agroecológica é realizada no centro histórico de Ilhéus, na Avenida Dois de Julho, ocorrendo todos os sábados, também no horário matutino, atualmente em espaço cedido por comerciantes locais que apoiam a iniciativa.

Com a proposta de incentivar a diversificação de produtos, a visibilidade do trabalho artesanal e estimular a cadeia consumidora local, a prefeitura municipal incentivou a participação dos núcleos de Economia Criativa da cidade também nessa feira, objetivando a cooperação entre os sistemas de produção e a equidade da cadeia de consumo que se organiza diante da oferta e procura de produtos livres de defensivos agrícolas e os que são oriundos do artesanato local. A participação dos núcleos de Economia Criativa aumentou o número de representantes do género feminino nas feiras estudadas.

Para Narciso e Henriques (2008: 3) as relações de género são um fator determinante e diferenciador da distribuição do trabalho, do rendimento, da riqueza, dos fatores produtivos e dos recursos naturais, que legitimam a importância feminina em relação aos costumes, tradições e valores socioculturais. Os saberes apreendidos no tempo, fruto da história, dos saberes adquiridos, fruto dos esforços no tempo recente, permitem às mulheres do meio rural se re-atualizarem, se recolocarem socialmente (Karam, 2004: 317).

Essas conquistas tornam-se maiores e mais representativas quando as mulheres se inserem e conquistam um lugar na cadeia de comércio popular o que por sua vez reflete as conquistas políticas, sociais, económicas e culturais alcançadas pela luta e engajamento político destas em movimentos sociais, que historicamente foram os principais meios de mobilização feminina na busca pelos direitos de igualdade de género em meio rural.

\section{Considerações finais}

Em jeito de sumula consideramos que os argumentos explicitados ao longo desse texto permitem a construção de um panorama inicial e não exaustivo sobre a produção científica que aborda a importância das mulheres na militância agroecológica. Dessa forma, muitos aspectos mencionados merecem um trabalho analítico mais aprofundado a ser desenvolvido por meio de metapesquisas, que abordem sobre determinados temas de interesse tanto para os pesquisadores ligados a área de agroecologia, quanto para a comunidade acadêmica de Agronomia e Ciências Sociais.

Conforme destacamos, a participação e a influência das mulheres nas feiras agroecológicas realizadas na cidade de Ilhéus vem-se expandindo, de modo a valorizar e certificar o compromisso das famílias agricultoras rurais locais com a ideia de produção agroecológica e orgânica.

Esse compromisso se fixa na preocupação que as mulheres produtoras rurais tem em oferecer a suas famílias, bem como também aos consumidores de seus produtos, um alimento livre de defensivos agrícolas e portanto mais saudável.

Entretanto, as dificuldades ainda enfrentadas no dia a dia, pelas mulheres do campo, tornam as suas atividades invisíveis na produção de alimentos, devido à dificuldade no acesso à terra e/ou à comercialização direta dos produtos produzidos pelas suas família. Além disso, essas mulheres ainda acumulam as tarefas do lar como: lavar, passar, cozinhar, limpar, cuidar dos filhos e do marido, entre outras.

Paralelamente estas atividades nem sempre são consideradas como trabalho pelas sociedades em que vivem e sim como obrigação do género feminino, desqualificando mais uma vez as suas atividades, apesar de cair sempre sobre as mulheres a acumulação das tarefas de casa e do campo.

Porém, é importante destacar que, na Cidade de Ilhéus, as mulheres do campo têm lutado pela igualdade de género e contribuem ativamente para a produção de alimentos básicos, sendo responsáveis por comercializar nas feiras agroecológicas da região mais de $70 \%$ dos géneros alimentícios produzidos, apesar das condições desiguais para homens e mulheres no campo. Desta forma, as mulheres do campo demonstram claramente a sua importância como protagonistas no processo de mudança no sistema de produção agrícola tradicional para o agroecológico, bem como no enfrentamento de ações assistencialistas, clientelistas e machistas.

Um dos fatores predominantes para esse aumento significativo da participação feminina nas feiras deve-se ao processo de luta constante destas em garantir o direito a estes espaços, o que as tem levado a organizar-se e inserir-se em núcleos de Economia Criativa, aumentando por sua vez o 
número de representantes do género feminino nas feiras agroecológicas.

Outro fator se deve à valorização, por parte dos consumidores, da presença feminina à frente das bancas nas feiras agroecológicas, gerando uma maior fidelização por parte destes, uma vez que esta maior confiabilidade é atribuída às mulheres, que para eles, representam a associação entre os conceitos "qualidade de vida" e "alimentos saudáveis".

Ficou expressa neste itinerário a importância das feiras agroecológicas na cidade de Ilhéus, Bahia, como espaços para geração de emprego e rendimentos, troca de saberes, valorização da cultura do campo, desconstrução de ideologias, atitudes e mentalidades discriminatórias e preconceituosas que regem a estrutura social da qual fazemos parte.

\section{Referências bibliográficas}

ALMEIDA, J., et al. (2014), "A invisibilidade parcial do trabalho feminino no campo das atividades produtivas", Anais $18^{\circ}$ REDOR - Perspectivas feministas de gênero: desafios no campo da militância e das práticas, Recife, Universidade Federal Rural de Pernambuco, pp. 3740-3750.

ÁLVAREZ, M. (2005), "La cocina como patrimonio (in) tangible", in V. Mariani (ed.), La cocina como patrimonio (in)tangible, pp. 11-25.

ASSIS, R. L. (2006), "Desenvolvimento rural sustentável no Brasil: perspectivas a partir da integração de ações públicas e privadas com base na agroecologia", Economia Aplicada, 10 (1), pp. 75-89.

BOURDIEU, P. (1989), La noblesse d'État. Grandes écoles et esprit de corps, Paris, Les Éditions de Minuit.

BRUMER, A. (2004), "Gênero e agricultura: a situação da mulher na agricultura do Rio Grande do Sul", Estudos feministas, 12 (1), pp. 205-227.

DEERE, C. (2004), "Os direitos da mulher à terra e os movimentos sociais rurais na reforma agrária", Estudos Feministas, 12 (1), pp.175-204.

FARAH, M. (2004), "Gênero e políticas públicas", Estudos feministas, 12 (1), pp. 47-71.

FERREIRA MENDES, M., et al. (2014), "A organização das mulheres extrativistas na região Sudoeste mato-grossense, Brasil", Estudos Feministas, 22 (1), pp. 71-89.

GARCIA, F. (2004), "A luta pela terra sob enfoque de gênero: os lugares da diferença no Pontal do Paranapanema", tese de Doutoramento em Geografia, Faculdade de Ciência e Tecnologia - Universidade Estadual Júlio de Mesquita Filho.

HEREDIA, B. e Rosângela Cintrão (2006), "Gênero e acesso a políticas públicas no meio rural brasileiro", Revista Nera, 9 (5), pp. 1-28.

HERRERA, K. (2013), "Uma análise do trabalho da mulher rural através da perspectiva da multifun- cionalidade agrícola", Anais Eletrônicos Seminário Internacional Fazendo Gêneros 10: desafios atuais dos feminismos, Florianópolis.

HOWKINS, J. (2001), The Creative Economy: How PeoPle Make Money from Ideas, London, Penguin Group.

KARAM, K. (2004), "A mulher na agricultura orgânica e em novas ruralidades", Revista Estudos Feministas, 12 (1), pp. 303-320.

LAMBARÉ D. (2014), "Manejo de variedades locales de Prunus persica (Rosaceae) en la Quebrada de Humahuaca, Argentina y su Relación con los Sistemas Agrícolas Tradicionales", Zonas Aridas, 15 (1), pp. 128-147.

LAMBARÉ, D.; Nilda VIGNALE e María Pochettino (2015), "Las ferias y festivales regionales como instancia de reafirmación del patrimonio biocultural en la quebrada de humahuaca (jujuy, argentina): el intercambio de duraznos (prunus persica)", Gaia Scientia, Edição Especial Etnobiologia na Argentina, 9 (3), pp. 7-16.

LE GOFF, J. (1992), O apogeu da cidade medieval, São Paulo, Martins Fontes.

MACCORMACK, C. e M. Strathern (eds.) (1980), Nature, Culture and Gender, Cambridge, Cambridge University Press.

MELO, L.A. de (2002), "Injustiças de gênero: o trabalho da mulher na agricultura familiar", XIII Encontro da Associação Brasileira de Estudos Populacionais, Ouro Preto-MG.

MELO, L.A. de (2006), "Crédito rural no Brasil: uma realidade para a mulher agricultora familiar?", Coordenação Geral de Estudos Ambientais e da Amazônia (CEAMB), Recife-PE, pp. 1-9.

MESQUITA, L. e Estevane Mendes (2012), "Mulheres na agricultura familiar: a comunidade Rancharia, Campo Alegre de Goiás (GO)", XXI Encontro Nacional de Geografia Agrária - Territórios em disputa: os desafios da geografia agrária nas contradições do desenvolvimento brasileiro, Universidade Federal de Uberlândia, Uberlândia.

NARCISO, V. e Pedro Henriques (2008), "O papel das mulheres no desenvolvimento rural: uma leitura para Timor-Leste", Centro de Estudos e Formação Avançada em Gestão e Economia, Universidade de Évora-Portugual, Working Paper.

PARGA, E. L. (1996), Entre fazendas, secos e molhados: o pequeno comércio na cidade do Rio de Janeiro (1850 - 1875), dissertação de Mestrado em História Social, Universidade Federal Fluminense.

RODRIGUES, P. (2012), "Os desafios e a superação da mulher na agricultura", Hortaliças em Revista, 1, pp. 7.

SALES, C. (2007), "Mulheres rurais: tecendo novas relações e reconhecendo direitos", Estudos Feministas, 15 (2), pp. 437-443.

SILIPRANDI, E. (2009), "Um olhar ecofeminista sobre as lutas por sustentabilidade no mundo rural", in P. Petersen (org.), Agricultura familiar camponesa na construção do futuro, pp.139-152. 
UNCTAD - UNITED NATIONS CONFERENCE ON TRADE AND DEVELOPMENT (2010), "Creative Economy: Feasible Development Option - UNPD/United
Nations", Creative Economy Report 2010. Disponível em: <unctad.org/en/Docs/ditctab20103en. pdf> [Último acesso: 09 out. 2016]

Recebido a 30/05/2016. Aceite para publicação a 11/11/2016.

Marcella Gomez (pereira.gomez@hotmail.com). Universidade Estadual de Santa Cruz-Bahia, Departamento de Ciências Biológicas. Campus Soane Nazaré de Andrade, Rodovia Jorge Amado, Km 16, Bairro Salobrinho, 45662-900 Ilhéus-Bahia, Brasil.

Emerson Antônio Rocha Melo de Lucena (lucenaemerson@yahoo.com.br). Universidade Estadual de Santa Cruz-Bahia, Brasil, Departamento de Ciências Biológicas. Campus Soane Nazaré de Andrade, Rodovia Jorge Amado, Km 16, Bairro Salobrinho, 45662-900 Ilhéus-Bahia, Brasil.

Ana Cristina de Souza Mandarino (anamandarino@gmail.com). Universidade Federal da Bahia, Escola de Administração \& Programa de Estudos, Pesquisas e Formação em Políticas e Gestão de Segurança Pública Brasil. Av. Reitor Miguel Calmon s/n - Vale do Canela, 30 andar, sala 27, 40.110-903 Salvador-Bahia, Brasil. Estélio Gomberg (egomberg@uesc.br). Universidade Estadual de Santa Cruz-Bahia, Departamento de Filosofia e Ciências Humanas. Campus Soane Nazaré de Andrade, Rodovia Jorge Amado, Km 16, Bairro Salobrinho, 45662-900 Ilhéus-Bahia, Brasil. 